\title{
Queuing System Modeling for Supermarkets
}

\author{
S. Maragathasundari, R.S.Somasundaram, P. Karunakaran, P. Manikandan
}

\begin{abstract}
Supermarkets may not have the IT needs that service-oriented businesses do, but that does not mean they cannot use computers in their day-to-day operations. Many supermarkets are adopting complex computer systems that allow them to regulate many of their practices, providing business leaders with more information to make decisions with and making some processes automatic, saving supermarkets both time and money. For the complete satisfaction of the customers, in system modeling, various queuing system is followed by the super markets. In all those queuing system, various queuing issue have to be dealt with. Among those, on of the Queuing problem is inspected and it is considered as a Non Markovian Queuing issues. For the above portrayed Queuing problem, by the usage of supplementary variable method, performance measures like number of customers in the system, average length of the queue, waiting time of the customers in the system as well as in the queue are derived. In addition, idle time of the server and the time spent by the server for each service are determined. The model is well justified by means of a Numerical portrayal and a grow graphical examination is done toward the end to favour the model.

Keywords: Performance measures, Non markovian Queue, Supplementary variable method.
\end{abstract}

\section{INTRODUCTION}

$\mathrm{M}$ arkets normally offer items at moderately low costs by utilizing their purchasing capacity to purchase products from makers at lower costs than littler stores can. They likewise limit financing costs by paying for merchandise in any event 30 days after receipt and some concentrate credit terms of 90 days or more from sellers. General stores compensate for their low edges by a higher by and large volume of offers, and with the clearance of higher-edge things purchased by the expected higher volume of customers. Self-administration with shopping baskets (trolleys) or bins decreases work cost, and numerous general store chains are endeavouring further decrease by moving to self-administration registration. "Reference [11] investigated and distinguished the shared characteristics" and contrasts between the general store industry and its coordination capacities in created financial matters. "Reference [3] looked at the business benefit is basic theoretical system chain to connecting with the worker fulfilment just as consumer loyalty and money related

Revised Manuscript Received on December 15, 2019.

* Correspondence Author

S. Maragathasundari*,Department of Mathematics, Kalasalingam Academy of Research and Education, Krishnankovil-626126, Tamilnadu. Email: maragatham01@gmail.com

R.S.Somasundaram, Department of Computer applications, Coimbatore Institute of

Technology,Coimbatore-641014,Tanukbadu,Email:somasundram73@gmai 1.com

P. Karunakaran, Department of Mathematics Kalasalingam Academy of Research and Education, Krishnankovil-626126,Tamilnadu. Email: karunamath1986@gmail.com

P. Manikandan, Department of Electronics and Communication Engineering, Kalasalingam Academy of Research and Education, Krishnankovil, Tamilnadu. Email: maanip85@gmail.com execution". "Reference [2] made a covering approach in Mobile adhoc frameworks". "Reference [10] investigated the difficulties of manual stock Administration framework for general stores and construes answers for these difficulties by arranging a mechanized machine controlled stock administration framework to request and refresh the stocks". Improvement of the grocery store the board framework dependent on business classification investigated by [13] "Reference [1] made a structure of a modernized stock administration framework for grocery stores". "Reference [4] recommended that mechanical advances have empowered general stores to complete the dependability cards conspire flawlessly". "Reference [9] have made an examination of a gathering section of association under long and short vacation". "Reference [12] researched the fundamental help for a three factor structure for grocery store administration quality as far as unwavering quality and legitimacy".

\section{QUEUEING SYSTEM IN SUPERMAKETS}

\section{A. Single server}

Supermarkets use a computer system called 'electronic point of sale' or EPOS to: Supermarket checkouts are called EPOS terminals

\section{B. Customers}

Customers are the buyers of the supermarket, can buy a great number of items among many brands, sizes and varieties.

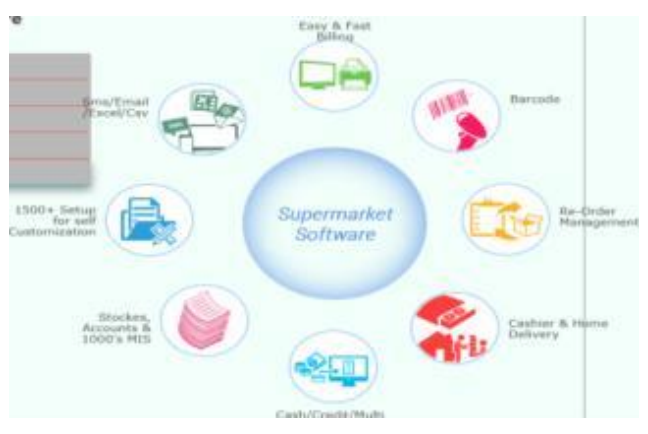

Fig. 1 Supermarket software

\section{Multi essential services (stage 1)}

- monitor and control stock;

- perform sales analysis;

- Collect information about clients utilizing steadfastness cards which offer focuses at whatever point cash is spent in the store. This information is utilized to examine the ways of managing money of clients and send them offers for the sort of items that they purchase consistently. 


\section{Queuing System Modeling for Supermarkets}

- Inventory PC frameworks are intended to monitor all stock that the grocery store has. These PCs are utilized as a component of the checkout procedure, and hold data on what supplies are on the racks, what supplies are in the distribution center and what the organization's required stock numbers are. Propelled frameworks can foresee deficiencies and naturally request new stock when fundamental. Indeed, even basic frameworks enable clients to check deals for precision and screen stock themselves.

- Other PC frameworks help grocery stores investigate deals information with the goal that directors can make better promoting plans. The PCs use stock frameworks to accumulate information on which items are selling, at that point break down the information to discover slants in specific items. This enables the advertising division to make an informed theory on what is selling admirably, and arrange the general store so these mainstream items are simpler to discover and are associated with advancements.

- RFID represents radio recurrence recognizable proof, a kind of standardized tag that emanates a radio recurrence. With the assistance of PC observing frameworks, markets can utilize RFID frameworks to follow items as they leave the racks and when they are looked at. This enables general stores to examine what items specific clients are purchasing (a similar way online markets do) and monitor stock as it moves all through the store. Supermarkets manage nutritional categories that need specific kinds of atmosphere control. The vegetables should be keeping sodden; the fish, meat, and dairy items should be refrigerated; and numerous general stores additionally have modern coolers that they keep additional provisions in. Markets use PCs to screen temperatures and conditions in these regions, making alterations when fundamental.

- As PCs become associated with an ever increasing number of frameworks all through the store, PCs will almost certainly interface the cards clients use for limits with the stock frameworks. As RFID frameworks become increasingly normal, general stores will most likely consequently complete exchanges and associate client data with the cards they use. This will make the procedure significantly increasingly customized and streamlined.

\section{Premise the arriving clients pick the sort of multi basic administration}

The client needs to enter the market, they need to pick their own merchandise or staple goods dependent on their own requirements. After choosing the things they need to go into the line for charging segment. The specialist of the store needs to nourish the subtleties of the client buy by methods FIFO (First in First Out) premise.

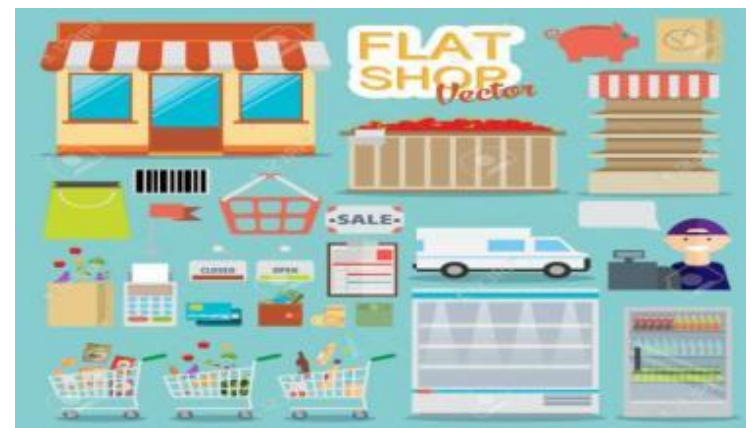

Fig. 2 Supermarket

\section{E. A product is sold the following sequence of events take place}

A standardized identification scanner is utilized to peruse the EAN number from the product. The EAN number is sent to the branch PC by the EPOS terminal. The branch PC utilizes the EAN number to look the stock document at the item's cost and portrayal which it sends back to the EPOS terminal. The branch PC refreshes the stock dimension for the item to demonstrate that one has been sold. The item's cost and depiction are shown at the EPOS terminal and imprinted on a receipt. The cost of the item is added to the aggregate of the items handled up until now.

\section{F. Optional service(Stage 2)}

For bill payment, there will be options provided to the customers as follows: 1.Cash mode 2.VISA Card 3.Credit Card 4.Debit Card 5.OnlineTransfer.

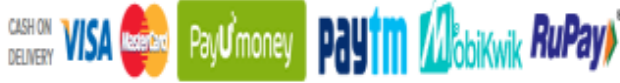

\section{G. Two sub stages of stage 2 of service}

For charge installment, the client will choose any one method of installment. While choosing such mode, they need to give their own one of kind ID for the primary stage. After handling that ID they will get some OTP or some other code will be produced by the financier and sent to the client's versatile number for installment affirmation as the second stage.

\section{H. Mandatory vacation (Long and short vacation)}

Subsequent to finishing the fundamental and discretionary administrations, the server will go for the necessary get-away. At the season of this mandatory short get-away the server will be very still, and it sent the regarded information to print the definite receipt for each customer. That printing time is said to be necessary get-away for our server. Consider a server in the general stores having continuous of information preparing it might be fixed or stucked at one point of time, right then and there the server can't ready to process the information sustained by the specialists of the market. Because of overloading the framework may get hanged for quite a while. Else the printer which is printing the receipt may turn out badly. The cartridge of the printer might be down. 


\section{Balking away amid long excursion}

A few organizations offer an assortment of exhaustive safeguard upkeep and crisis support administrations for grocery stores. Some completely prepared administration experts give fast and proficient fix benefits that diminish costly gear down time. This may not occur at all the occasions, at certain moments the server requires a type of programming advancement process. Amid this procedure, the server will be icon to finish the product upgradation process. This causes woofing; the clients will become upset while remaining in the line amid framework support. Programming advancement is an intricate procedure. The complexities engaged with programming improvement makes entanglements like miscommunication, scope changes and due dates named by numerous a product advancement organization as a component of the "creation process. These traps make clients bothered and they will in general leave from the line by becoming upset. Consequently they will check for exchange choices they will leave the line.

\section{J. Long vacation}

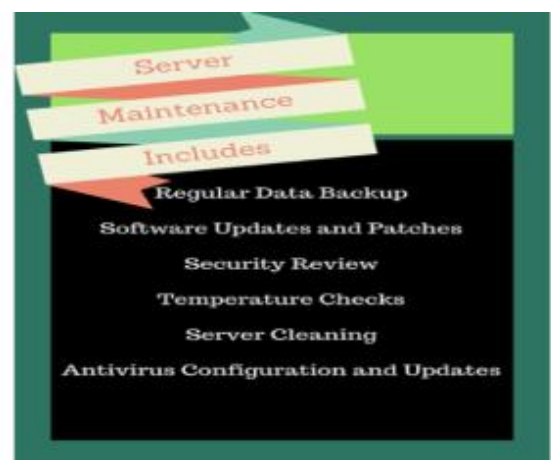

\section{K. Reneging}

Amid short vacation, the server procures maintenance work intermittently by methods for reneging occurs. The clients who are remaining in the line become annoyed. Henceforth they leave the line lastly leaves the system. Sometime a short time later, they join the line for administration.

\section{Points of interest of EPOS frameworks in general stores include}

Shelves are in every case all around loaded, new sustenance is promptly accessible and items all around seldom run out; Customers can be managed considerably more rapidly at the checkout; Customers get a completely separated receipt; Goods can be paid for utilizing electronic supports exchange (EFT);Accurate and cutting-edge deals examination data is constantly accessible for managers; Customer purchasing behaviors can be broke down and used to target clients with offers for products and ventures that they may be keen on .

The above Queuing issue of general stores has been laid out as a Mathematical marvels in the accompanying section. For the relating Queuing issue, suspicions, definitions hidden the model has been explained. The issue is illuminated by valuable variable strategy which gives out all the required Queuing execution proportions of the framework followed in the super markets. Numerical part discovers the points of interest and downsides of the Queuing framework followed in the system. In expansion, graphical partstill more picturizes the lining framework characterized in the framework demonstrating grocery stores.

\section{Mathematical Description Of The QUEUING SYSTEM IN SUPERMARKETS}

This review investigates a Non Markovian covering issues in which the association is rendered in two phases. Clients get together in bundles looks for after a Poisson task. Administration time looks for after general distribution. Multi basic administrations are offered in the primary phase of administration. Next the second phase of administration is optional. The discretionary administration is rendered in two phases. After the satisfaction of the second time of association, the server goes for a required excursion, both of long term or brief span dependent on need of the server. Here get-away in the sense tends to the period amidst which the assistance endeavors to improve the condition of the server. What's more, clients due to impatience leave the framework without getting the administration even in the wake of joining the queue. This concept of reneging is considered amid short vacation. Moreover amid the season of long get-away, because of the stretch of the queue, customers follow the idea of Balking. That is without joining the queue, the customers leave the system.

For the above portrayed Queuing model, by strategies for the fortifying variable framework, we get the persisting state results in express and close to respect the probability creating capacities with respect to the amount of customers in the line, the typical number of customers, idle time of the server, use factor and the ordinary holding up time in the line. The model is well justified by means of a practical Example. Numerical portrayal and agrow graphical examination are done toward the end to favour the model.

\section{ASSUMPTIONS UNDERLYING THE MODEL}

Clients arrive in batches to the system modelling supermarkets with mean arrival rate $\xi \xi>0 . \xi m_{r}((\mathrm{r}=1$ to $\mathrm{n})$ be the first order probability that a batch of $r$ customers arrives at the system. Here $0 \leq m_{r} \leq 1$ and $\sum_{r=1}^{n} m_{r}=1$. For the first stage of service (Multi essential services), $K_{n .1 j}(x) \tau_{1 j}(x)$ is the conditional probability of completion of completion of first stage of service. The probability distribution function of the first stage of service and its corresponding density function are given by $D_{1 j}^{*}(x)$ and $d_{1 j}^{*}(x) d_{1 j}^{*}(x)$.

$$
\text { Hence } \tau_{1 j}(x)=\frac{d_{1 j}^{*}(x)}{1-D_{1 j}^{*}(x)}, \quad d_{1 j}^{*}(s)=\tau_{1 j}(s) e^{-\int_{0}^{s} \tau_{1 j}(x) d x} \text {. }
$$

Similarly for the second sub stage $S_{n, 2}^{(1 i)}(x)$, second sub stage $2 S_{n, 2}^{(2)}(x)$, long vacation $Q_{n}^{(L)}(x, z)$ and short vacation $Q_{n}^{(S)}(x)$, we have the following:

$$
\begin{gathered}
\eta_{2}^{(1 i)}(x)=\frac{d_{2}^{(1 i) *}(x)}{1-D_{2}^{(1 i) *}(x)}, d_{2}^{(1 i) *}(s)=\eta_{2}^{(1 i)}(s) e^{-\int_{0}^{s} \eta_{2}^{(1 i)}(x) d x} \\
\eta_{2}^{(2)}(x)=\frac{d_{2}^{(2) *}(x)}{1-D_{2}^{(2) *}(x)}
\end{gathered}
$$




\section{Queuing System Modeling for Supermarkets}

$d_{2}^{(2) *}(s)=\eta_{2}^{(2)}(s) e^{-\int_{0}^{s} \eta_{2}^{(2)}(x) d x}$

$$
\gamma^{(L)}(x)=\frac{d_{3}^{(L) *}(x)}{1-D_{3}^{(L) *}(x)}
$$

$d_{3}^{(L) *}(s)=\gamma^{(L)}(s) e^{-\int_{0}^{S} \gamma^{(L)}(x) d x}$

$$
\gamma^{(s)}(x)=\frac{d_{4}^{(S) *}(x)}{1-D_{4}^{(S) *}(x)}
$$

$d_{4}^{(S) *}(s)=\gamma^{(s)}(s) e^{-\int_{0}^{s} \gamma^{(s)}(x) d x}$

All the stages of service, long vacation and short vacation follows general distribution. Arrival of customers in batches follows Poisson distribution. The concept of Reneging acts during short vacation following exponential distribution with parameter $\beta$.

Balking with parameter $b_{2}$ is considered during the time of long vacation.

We define the probability generation function as follows:

$$
\begin{aligned}
& K_{n, 1 j}(x, z)=\sum_{n=0}^{\infty} z^{n} K_{n, 1 j}(\mathrm{x}) \\
& S_{n, 2}^{(1 i)}(x, z)=\sum_{n=0}^{\infty} z^{n} S_{n, 2}^{(1 i)}(x) \\
& S_{n, 2}^{(2)}(x, z)=\sum_{n=0}^{\infty} z^{n} S_{n, 2}^{(2)}(x) \\
& Q_{n}^{(L)}(x, z)=\sum_{n=0}^{\infty} z^{n} Q_{n}^{(L)}(x) \\
& Q_{n}^{(S)}(x, z)=\sum_{n=0}^{\infty} z^{n} Q_{n}^{(S)}(x)
\end{aligned}
$$

Next, the problem is depicted by birth and death process of queuing theory and the equations governing the model is described below based on the queuing system carried out in supermarkets.

\section{Governing Equations Of The Model}

$\frac{d}{d x} K_{n, 1 j}(x)+\left(\xi+\tau_{1 j}(x)\right) K_{n, 1 j}(x)=\xi \sum_{r=1}^{n} m_{r} K_{n-r, 1 j}(x)$

$\frac{d}{d x} K_{0,1 j}(x)+\left(\xi+\tau_{1 j}(x)\right) K_{0,1 j}(x)=0$.

(2)

$\frac{d}{d x} S_{n, 2}^{(1 i)}(x)+\left(\xi+\eta_{2}^{(1 i)}(x)\right) S_{n, 2}^{(1 i)}(x)=$

$\xi \sum_{r=1}^{n} m_{r} S_{(n, 2)-r}^{(1 i)}(x)$.

$\frac{d}{d x} S_{0,2}^{(1 i)}(x)+\left(\xi+\eta_{2}^{(1 i)}(x)\right) S_{0,2}^{(1 i)}(x)=0$.

$\frac{d}{d x} S_{n, 2}^{(2)}(x)+\left(\xi+\eta_{2}^{(2)}(x)\right) S_{n, 2}^{(2)}(x)=\xi \sum_{r=1}^{n} m_{r} S_{(n, 2)-r}^{(2)}(x)$.

$\frac{d}{d x} S_{0,2}^{(2)}(x)+\left(\xi+\eta_{2}^{(2)}(x)\right) S_{0,2}^{(2)}(x)=0$.

$\frac{d}{d x} Q_{n}^{(L)}(x)+\left(\xi+\gamma^{(L)}(x)\right) Q_{n}^{(L)}(x)=$

$\xi b_{2} \sum_{r=1}^{n} m_{r} Q_{n-r}^{(L)}(x)+$

$\xi\left(1-b_{2}\right) Q_{n}^{(L)}(x)$.

(7)

$\frac{d}{d x} Q_{0}^{(L)}(x)+\left(\xi+\gamma^{(L)}(x)\right) Q_{0}^{(L)}(x)=\xi\left(1-b_{2}\right) Q_{0}^{(L)}(x)$.

(8)

$\frac{d}{d x} Q_{n}^{(S)}(x)+\left(\xi+\gamma^{(S)}(x)+\beta\right) Q_{n}^{(S)}(x)=$

$\xi \sum_{r=1}^{n} m_{r} Q_{n-r}^{(S)}(x)+\beta Q_{n+1}^{(S)}(x)$.

(9)

$\frac{d}{d x} Q_{0}^{(S)}(x)+\left(\xi+\gamma^{(S)}(x)\right) Q_{0}^{(S)}(x)=\beta Q_{1}^{(S)}$.

(10)

$\xi F=\int_{0}^{\infty} Q_{0}^{(S)}(x) \gamma^{(S)}(x) d x+$ $\int_{0}^{\infty} Q_{0}^{(L)}(x) \gamma^{(L)}(x) d x$.

(11) The above conditions are to be solved using the boundary conditions given below:

$K_{n .1 j}(0)=\xi m_{n+1} F+\int_{0}^{\infty} Q_{n+1}^{(S)}(x) \gamma^{(S)}(x) d x+$ $\int_{0}^{\infty} Q_{n+1}^{(L)}(x) \gamma^{(L)}(x) d x$.

$\int_{0}^{\infty} K_{n, 1 j}(x) \tau_{1 j}(x) d x$.

$S_{n, 2}^{(2)}(0)=\int_{0}^{\infty} S_{n, 2}^{(1 i)}(x) \eta_{2}^{(1 i)}(x) d x$

$Q_{n}^{(S)}(0)=$

$C_{1} \int_{0}^{\infty} S_{n, 2}^{(2)}(x) \eta_{2}^{(2)}(x) d x$

(15)

$Q_{n}^{(L)}(0)=C_{2} \int_{0}^{\infty} S_{n, 2}^{(2)}(x) \eta_{2}^{(2)}(x) d x$.

(16)

On taking $\sum_{n=1}^{\infty} e q(1) z^{n}$, we get

$\frac{d}{d z} K_{n .1 j}(x, z)+\left(\xi-\xi M(z)+\tau_{1 j}(x)\right) K_{n .1 j}(x, z)=0$.

Similarly from the second stage second sub stages, phases of vacation, we have

$\frac{d}{d z} S_{n, 2}^{(1 i)}(x, z)+\left(\xi-\xi M(z)+\eta_{2}^{(1 i)}(x)\right) S_{n, 2}^{(1 i)}(x, z)=0(18)$
$\frac{d}{d z} S_{n, 2}^{(2)}(x, z)+\left(\xi-\xi M(z)+\eta_{2}^{(2)}(x)\right) S_{n, 2}^{(2)}(x, z)=0$.

$\frac{d}{d z} Q_{n}^{(S)}(x, z)+$

$\left(\xi-\xi M(z)+\gamma^{(S)}(x)+\beta-\frac{\beta}{z}\right) Q_{n}^{(S)}(x, z)=0$

$\frac{d}{d z} Q_{n}^{(L)}(x, z)+\left(b_{2}(\xi-\xi M(z))+\gamma^{(L)}(x)\right) Q_{n}^{(L)}(x, z)=0$.

As the process gets repeated from boundary conditions, we get

$z K_{n .1 j}(0, z)=\xi M(z) F+\int_{0}^{\infty} Q^{(L)}(x, z) \gamma^{(L)}(x) d x-$

$000 Q 0 L x, z \gamma L x d x+000 Q S x, z \gamma S x d x-000 Q 0 S x, z \gamma S x d x$

From (11), we have

$z K_{n .1 j}(0, z)=\xi F(M(z)-1)+\int_{0}^{\infty} Q^{(L)}(x, z) \gamma^{(L)}(x) d x+$ $000 Q S x, z \gamma S x d x$.

(22)

$S_{2}^{(1 i)}(0, z)=\int_{0}^{\infty} K_{1 j}(x, z) \tau_{1 j}(x) d x$.

(23)

$S_{2}^{(2)}(0, z)=\int_{0}^{\infty} S_{2}^{(1 i)}(x, z) \eta_{2}^{(1 i)}(x) d x$

$Q_{n}^{(S)}(0, z)=c_{1} \int_{0}^{\infty} S_{2}^{(2)}(x) \eta_{2}^{(2)}(x) d x$.

(25)

$Q_{n}^{(L)}(0, z)=c_{2} \int_{0}^{\infty} S_{2}^{(2)}(x) \eta_{2}^{(2)}(x) d x$.

(26)

Now integrating (17) - (21) between limits 0 and, we get $K_{1 j}(x, z)=$

$K_{1 j}(0, z) e^{-[\xi-\xi M(z)] x-\int_{0}^{x} \tau_{1 j}(t) d t}$.

$S_{2}^{(1 i)}(x, z)=S_{2}^{(1 i)}(0, z) e^{-[\xi-\xi M(z)] x-\int_{0}^{x} \eta_{2}^{(1 i)}(t) d t}$.

$S_{2}^{(2)}(x, z)=S_{2}^{(2)}(0, z) e^{-[\xi-\xi M(z)] x-\int_{0}^{x} \eta_{2}^{(2)}(t) d t}$.

(29)

$Q^{(S)}(x, z)=$ 
$Q^{(S)}(0, z) e^{-[\xi-\xi M(z)] x-\int_{0}^{x} \gamma^{(S)}(t) d t .}$

$Q^{(L)}(x, z)=Q^{(L)}(0, z) e^{-[\xi-\xi M(z)] x-\int_{0}^{x} \gamma^{(L)}(t) d t .}$

(31)

Again integrating (27) - (31) by parts with respect to, we get $K_{1 j}(z)=K_{1 j}(0, z)\left[\frac{1-D_{1 j}^{*}(\xi-\xi M(z))}{\xi-\xi M(z)}\right]$.

$S_{2}^{(1 i)}(z)=S_{2}^{(1 i)}(0, z)\left[\frac{1-D_{2}^{(1 i) *}(\xi-\xi M(z))}{\xi-\xi M(z)}\right]$.

$S_{2}^{(2)}(z)=S_{2}^{(2)}(0, z)\left[\frac{1-D_{2}^{(2) *}(\xi-\xi M(z))}{\xi-\xi M(z)}\right]$.

$Q^{(L)}(z)=Q^{(L)}(0, z)\left[\frac{1-D_{3}^{(L) *}\left(b_{2}(\xi-\xi M(z))\right)}{b_{2}(\xi-\xi M(z))}\right]$.

$Q^{(S)}(z)=Q^{(S)}(0, z)\left[\frac{1-D_{4}^{(S) *}\left(\xi-\xi M(z)+\beta-\frac{\beta}{z}\right)}{\xi-\xi M(z)+\beta-\frac{\beta}{z}}\right]$.

(36)

Multiply (32) by $\tau_{1 j}(x)$ on both sides and integrating over $x$, we get

(37)

Using the corresponding probability completion, we get $\int_{0}^{\infty} S_{2}^{(1 i)}(x, z) \eta_{2}^{(1 i)}(x) d x=$

$K 1 j 0, z D 1 j * \xi-\xi M z D 21 i * \xi-\xi M z$

(38)

$\int_{0}^{\infty} S_{2}^{(2)}(x, z) \eta_{2}^{(2)}(x) d x=$

$K 1 j 0, z D 1 j * \xi-\xi M z D 21 i * \xi-\xi M z D 22 * \xi-\xi M z$.

(39)

$\int_{0}^{\infty} Q^{(L)}(x, z) \gamma^{(L)}(x) d x=$

$c 2 K 1 j 0, z D 1 j * \xi-\xi M z D 21 i * \xi-\xi M z D 22 * \xi-\xi M z D 3 L * b 2 \xi$

$-\xi M Z$

$\int_{0}^{\infty} Q^{(S)}(x, z) \gamma^{(S)}(x) d x=$

$c 1 K 1 j 0, z D 1 j * \xi-\xi M z D 21 i * \xi-\xi M z D 22 * \xi-\xi M z D 4 S * \xi-\xi$ $M z+\beta-\beta z$.

(41)

Using (40) and (41) in (22), we get

$$
\begin{aligned}
K_{n, 1 j}(0, z)= & \frac{\xi F(M(z)-1)}{z-D_{1 j}^{*}(\xi-\xi M(z)) D_{2}^{(1 i) *}(\xi-\xi M(z)) D_{2}^{(2) *}(\xi-\xi M(z))} . \\
& {\left[c_{2} D_{3}^{(L) *}\left(b_{2}(\xi-\xi M(z))\right)+c_{1} D_{4}^{(S) *}\left(\xi-\xi M(z)+\beta-\frac{\beta}{z}\right)\right] }
\end{aligned}
$$

Substituting (42) in (32) - (36), we get

$K_{1 j}(z)=\frac{-F\left[1-D_{1 j}^{*}(\xi-\xi M(z))\right]}{D(z)}$.

(43)

$S_{2}^{(1 i)}(z)=\frac{-F\left[D_{1 j}^{*}(\xi-\xi M(z))\right]\left[1-D_{2}^{(1 i) *}(\xi-\xi M(z))\right]}{D(z)}$.

$S_{2}^{(2)}(z)=$ $\int_{0}^{\infty} K_{1 j}(x, z) \tau_{1 j}(x) d x=K_{1 j}(0, z) D_{1 j}^{*}(\xi-\xi M(z))$.

$\frac{-F D_{1 j}^{*}(\xi-\xi M(z)) D_{2}^{(1 i) *}(\xi-\xi M(z))\left[1-D_{2}^{(2) *}(\xi-\xi M(z))\right]}{D(z)}$.

$$
Q^{(L)}(z)=\frac{-F c_{2} D_{1 j}^{*}(\xi-\xi M(z)) D_{2}^{(1 i) *}(\xi-\xi M(z))}{D_{2}^{(2) *}(\xi-\xi M(z))\left[\frac{1-D_{3}^{(L) *}\left(b_{2}(\xi-\xi M(z))\right)}{b_{2}}\right]} .
$$

$$
\begin{aligned}
& Q^{(S)}(z) \\
& -F c_{1} D_{1 j}^{*}(\xi-\xi M(z)) D_{2}^{(1 i) *}(\xi-\xi M(z)) D_{2}^{(2) *}(\xi-\xi M(z)) \\
& \xi(M(z)-1)\left[\frac{1-D_{4}^{(S) *}\left(\xi-\xi M(z)+\beta-\frac{\beta}{z}\right)}{\xi-\xi M(z)+\beta-\frac{\beta}{z}}\right] \\
& D(z)
\end{aligned}
$$

\section{PROBABILITY GENERATING FUNCTION OF THE QUEUE SIZE}

Let $E_{q}(z)$ be the probability generating function of the Queue size.

$$
\begin{aligned}
E_{q}(z)=K_{1 j}(z)+ & S_{2}^{(1 i)}(z)+S_{2}^{(2)}(z)+Q^{(L)}(z)+Q^{(S)}(z) \\
& =\frac{N(Z)}{D(z)}
\end{aligned}
$$

Where

\section{Where}

$$
\begin{aligned}
& D(z)=z-D_{1 j}^{*}(\xi-\xi M(z)) D_{2}^{(1 i) *}(\xi-\xi M(z)) D_{2}^{(2) *}(\xi- \\
& \xi M(z))\left[c_{2} D_{3}^{(L) *}\left(b_{2}(\xi-\xi M(z))\right)+c_{1} D_{4}^{(S) *}(\xi-\xi M(z)+\right. \\
& \left.\left.\beta-\frac{\beta}{z}\right)\right] N(z)=-F\left\{\left(1-D_{1 j}^{*}(\xi-\xi M(z))\right)+D_{1 j}^{*}(\xi-\right. \\
& \xi M(z))\left[\left(1-D_{2}^{(1 i) *}(\xi-\xi M(z))\right)+D_{2}^{(1 i) *}(\xi-\xi M(z))\{(1-\right. \\
& \left.D_{2}^{(2) *}(\xi-\xi M(z))\right)+ \\
& D_{2}^{(2) *}(\xi-\xi M(z))\left(c_{1}\left[\frac{-D_{3}^{(1) *}\left(b_{2}(\xi-\xi M(z))\right)}{b_{2}}\right]-c_{1} \xi(M(z)-\right. \\
& \left.\left.\left.\left.1)\left[\frac{1-D_{4}^{(s) *}\left(\xi-\xi M(z)+\beta-\frac{\beta}{z}\right)}{\xi-\xi M(z)+\beta-\frac{\beta}{z}}\right]\right)\right\}\right]\right\}
\end{aligned}
$$

\section{STEADY STATE ARRANGEMENT OF THE QUEUE SIZE}

Let $L_{q}$ a chance to demonstrate the reliable state typical number of customers in the line. By then

$L_{q}=\left.\frac{d}{d z} D_{q}^{*}(z)\right|_{z=1}=\left.\frac{d}{d z}\left\{\frac{N(Z)}{D(Z)}\right\}\right|_{Z=1}$

Where $N(Z)$ and $D(Z)$ are the numerator and denominator of equation (27).

Since $D_{q}^{*}(z)=\frac{0}{0}$ at $=1$, we utilize two fold separation and get

$$
\begin{aligned}
& L_{q}=\lim _{z \rightarrow 1} \frac{d}{d z} D_{q}^{*}(z)=\frac{D^{\prime}(1) N^{\prime \prime}(1)-D^{\prime \prime}(1) N^{\prime}(1)}{2\left(D^{\prime}(1)\right)^{2}} \\
& D^{\prime}(1)=1-\left\{\left[E\left(D_{1 j}\right)+E\left(D_{2}^{(1 i)}\right)+E\left(D_{2}^{(2)}\right)\right] \xi\left(c_{1}+c_{2}\right)+\right. \\
& c 2 b 1 \xi E D 3(L)-c 1-\xi+\beta E D 4(S)
\end{aligned}
$$

$$
\begin{aligned}
& D^{\prime \prime}(1)=\left(c_{1}+c_{2}\right)(-\xi)\left\{\xi E\left(D_{2}^{(2)}\right)\left[E\left(D_{1 j}\right)+E\left(D_{2}^{(1 i)}\right)\right]+\right. \\
& \xi\left(E\left(D_{1 j}^{2}\right)+E\left(D_{2}^{(1 i)^{2}}\right)\right)- \\
& \xi\left\{E\left(D_{1 j}\right) E\left(D_{2}^{(2)}\right)+\right. \\
& E\left(D_{2}^{(1 i)}\right) E\left(D_{2}^{(2)}\right)-
\end{aligned}
$$




\section{Queuing System Modeling for Supermarkets}

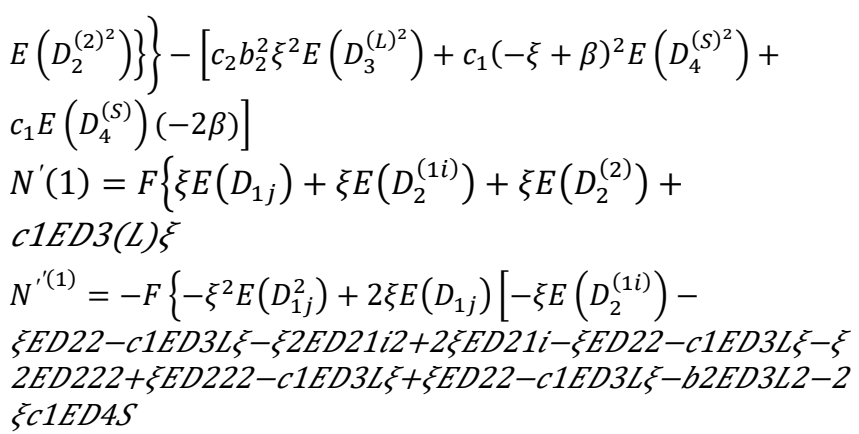

Further the mean waiting time of a customer can be found using Little's formula

$$
L=L_{q}+\rho, W_{q}=\frac{L_{q}}{\lambda}, W=\frac{L}{\lambda}
$$

\section{NUMERICAL JUSTIFICATION}

Assume that service time follows exponential distribution in particular and based on this condition, the numerical justification is elaborated below:

The values are collected accordingly: $E\left(D_{1 j}\right)=\frac{1}{\tau_{1 j}}$, $E\left(D_{1 j}^{2}\right)=\frac{2}{\tau_{1 j}^{2}} \quad, \quad E\left(D_{2}^{(1 i)}\right)=\frac{1}{\eta_{2}^{(1 i)}} \quad, \quad E\left(D_{2}^{(1 i)^{2}}\right)=\frac{2}{\eta_{2}^{(1 i)^{2}}}$ , $E\left(D_{2}^{(2)}\right)=\frac{1}{\eta_{2}^{(2)}}, E\left(D_{2}^{(2)^{2}}\right)=\frac{2}{\eta_{2}^{(2)^{2}}} \quad, E\left(D_{3}^{(L)}\right)=\frac{1}{\gamma^{(L)}}$, $E\left(D_{4}^{(S)}\right)=\frac{1}{\gamma^{(S)}}, E\left(D_{3}^{(L)^{2}}\right)=\frac{2}{\gamma^{(L)^{2}}} \quad, \quad E\left(D_{4}^{(S)^{2}}\right)=\frac{2}{\gamma^{(S)^{2}}}$, $c_{1}=0.6, c_{2}=0.4, \xi=3, b_{2}=1, \eta_{2}^{(1 i)}=3, \eta_{2}^{(2)}=4$, $\gamma^{(S)}=4, \beta=4.5, \tau_{1 j}=3, \gamma^{(L)}=2$

Table- I: Effect of Variation of Reneging $\beta=$

\begin{tabular}{|c|c|c|c|c|c|}
\hline$Q$ & $\rho$ & $L_{q}$ & $W_{Q}$ & $L$ & $W$ \\
\hline 0.3680 & 0.6320 & 1.5547 & 0.5182 & 2.1867 & 0.7289 \\
\hline 0.3596 & 0.6404 & 1.5317 & 0.5106 & 2.1721 & 0.7240 \\
\hline 0.3511 & 0.6489 & 1.4831 & 0.4944 & 2.1320 & 0.7107 \\
\hline 0.3423 & 0.6577 & 1.4029 & 0.4676 & 2.0606 & 0.6869 \\
\hline 0.3333 & 0.6667 & 1.2837 & 0.4279 & 1.9504 & 0.6501 \\
\hline 0.3241 & 0.6759 & 1.1161 & 0.3720 & 1.7920 & 0.5973 \\
\hline
\end{tabular}

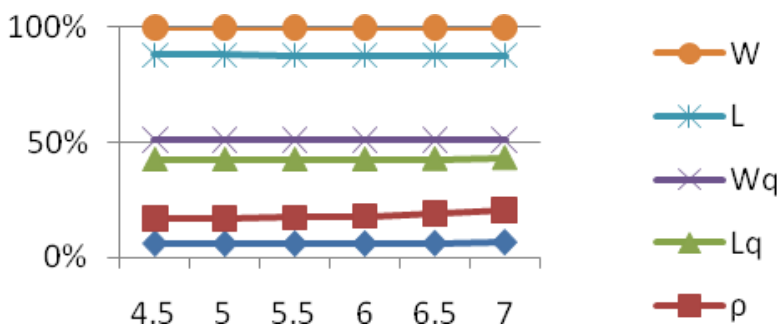

Fig.3. Variation of $\beta$

Table- II: Effect of Variation of Service in the $1^{\text {st }}$ Stage $\tau_{1 j}=4,5,6,7,8$

\begin{tabular}{|c|c|c|c|c|c|}
\hline$Q$ & $\rho$ & $L_{q}$ & $W_{Q}$ & $L$ & $W$ \\
\hline 0.3840 & 0.6160 & 1.5423 & 0.5141 & 2.1583 & 0.7194 \\
\hline 0.3831 & 0.6169 & 1.5019 & 0.5006 & 2.1188 & 0.7063 \\
\hline 0.3825 & 0.6175 & 1.4724 & 0.4908 & 2.0899 & 0.6966 \\
\hline 0.3820 & 0.6180 & 1.4499 & 0.4833 & 2.0679 & 0.6893 \\
\hline 0.3816 & 0.6184 & 1.4323 & 0.4774 & 2.0507 & 0.6836 \\
\hline
\end{tabular}

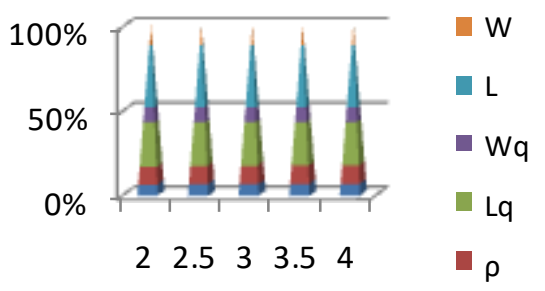

Fig.5. Variation of $\gamma^{(L)}$

\section{NUMERICAL STUDY}

Under this examination, three ideas are discussed. To begin with, in table 1 , as the likelihood of reneging increases, that is because of restlessness the clients leave the framework in the wake of joining the queue. Due to this the length of the line gets reduced. Simultaneously the other presentation estimates like holding up time of the customers in the line just as in the framework additionally gets lessen. Next the idea of likelihood of culmination of first stage of administration has been analyzed. The measure of time spent by the server for administration gets expanded and consequently the inactive time of the server gets lessen. It likewise prompts the all the line execution measures to get reduced. Finally, as the likelihood of finish of long get-away builds, the mean length of the line, number of clients in the framework, holding up time of the clients in the framework just as in the line gets lessens. All the qualities are true to form 


\section{CONCLUSION}

In this examination, we have taken a lining issue occurring in a framework demonstrating supermarket. Method of strengthening variable is connected to understand the lining problem. As an outcome all the line execution measures are derived. The lining issue is analyzed by numerical investigation too by a graphical work. All the lining issues occurring, all things considered, circumstances can be contemplated by this lining approach. Even if the lining issue comprising of periods of administration, multi get-away strategies, shut down time work, set up time work, administration intrusion, fix process and so on., can be very much broke down by this lining approach.

\section{REFERENCES}

1. A. Abisoye opeyemi, Boboye fatoba and O. Abisoye blessing, "Design of a computerized inventory management system for supermarkets",International Journal of Science and Research, vol. 2, no. 9, 2013, pp.340-344.

2. Dhanalakshmi and S. Maragathasundari, "Mobile adhoc networks problem- A queueing approach", International journal of communication networks and distributed systems, vol.21, no.4, 2018.

3. W. Gary and Loveman, "Employee satisfaction, customer loyalty, and financial performance:An empirical examination of the service profit chain in retail banking", Journal of Service Research, vol.1, no.1, 1998, pp.18-31.

4. Ibrahim Muhammad Hassan, "The use of loyalty cards by supermarkets: a review of literature", International Journal of Scientific and Engineering Research, vol.9, no.12, 2018, pp.260-263.

5. K.C . Madan and A.Z . Abu-Dayyeh, "On a single server queue with optional phase type server vacations based on exhaustive deterministic service and a single vacation policy", Applied Mathematics and Computation, vol.149, no.3, 2004, pp. 723-734.

6. K.C. Madan and G. Chodhury, "An $\mathrm{M}^{[\mathrm{x}]} / \mathrm{G} / 1$ queue with Bernoulli vacation schedule under restricted admissibility policy", Sankhaya, Vol.66, 2004, pp.172-193.

7. S. Maragathasundari, "A bulk arrival queueing model of three stages of service with different vacation policies,service interruption and delay time", American International Journal of Research in Science, Technology, Engineering\& Mathematics, vol.11, no.1, 2015, pp.52-56.

8. S. Maragathasundari and S. Srinivasan, "Analysis of $M / G / 1$ feedback queue with three stage and multiple server vacation", Applied mathematical sciences,vol.6, no.125, 2012, pp.6221-6240.

9. S. Maragathasundari and K. Karthikeyan, "A bulk queueing model of optional second phase service with short and long vacations", International Journal of scientific research in science and technology, vol.2, no.5, 2016.

10. M. Rajeswari, M. Parvathi, G. Savitha, S. Shirley, "The survey on inventory management system for supermarket using android application", International Journal Of Innovative Research In Computer and Communication Engineering,vol. 4, no.2, 2016, pp.2380-2384.

11. Sameerkumar, "A study of the supermarket industry and its growing logistics capabilities", International Journal of Retail and Distribution Management, vol. 36, n0. 3, 2008, pp.192-211.

12. P. F. Venter , M. Dhurup, "Consumer perceptions of supermarket service quality:Scale development and validation",South African Journal of Economic and Management Sciences, vol. 8, n0.4, 2005, pp.424-436.

13. Xiumei zhu, Zhichengshi, Yingchunzhang and Feifeiliu, "Improvement of the supermarket management system based on commercial category", International Journal of Electronics and Electrical Engineering, vol. 1, no. .2, 2013, pp.72-75.

\section{AUTHORS PROFILE}

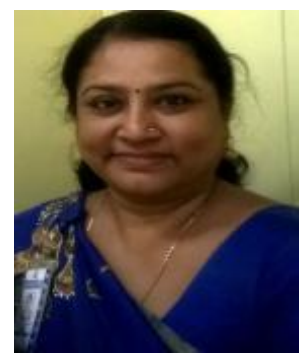

Dr.S. Maragatha Sundari acquired her B.Ed. degree from V.O.C Teachers College, Tuticorin in 1993. She got her M.Sc. in Mathematics from Manonmaniam Sundaranar University; Tirunelveli in 1995 and her M.Phil degree from Madurai Kamaraj University, Madurai in 2003. She did her Ph.D. in Sathyabama University, Chennai, India. She has more than 17 years of instructing knowledge. She has distributed more than 50 inquire about papers in national and international journals. She has displayed and distributed papers at national and international conferences. She is right now filling in as an Associate Professor in the Department of Mathematics in Kalasalingam Academy of Research And Education, Anand Nagar, Tamilnadu, Krishnankovil-626126, India. In addition, she is doing her research guidance for five research scholars.

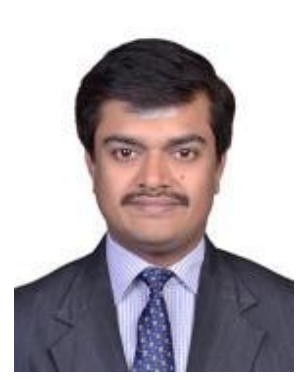

Dr. R. S. Somasundaram is the Professor and Head in the Department of Computer Applications at Coimbatore Institute of Technology, Coimbatore, TamilNadu, India. He received his $\mathrm{Ph} . \mathrm{D}$ in Computer Science from Bharathiar University, Coimbatore in 2014. He received his Bachelor degree in Mathematics from Madurai Kamaraj University, Madurai in 1993 and Masters degree in Computer Applications from Madurai Kamaraj University, Madurai in 1996. He got qualified as cost accountant in 1996. He also secured his M.Phil in Computer Science from Bharathiar University in 2005. He has more than 23 years of experience in India and abroad. He has published about 10 research articles in various refereed journals. He is a reviewer of various journals. He is a member of various professional societies such as ISTE, CSI, IEEE, ACM-CSTA, etc. His research interests includes Queuing theory,Data Mining, Data compression.

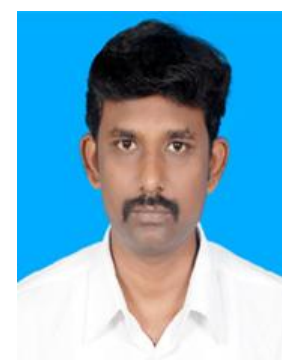

Mr. P. Karunakaran pursued his B.Sc degree from Ayya Nadar Janaki Ammal College, Sivakasi in 2009. He got his M.Sc. degree from Ayya Nadar Janaki Ammal College, Sivakasi in 2012. He obtained his M.Phil. degree from Ayya Nadar Janaki Ammal College, Sivakasi in 2013 He had 6 years of teaching experience. Now he is doing research area in Queuing Theory in Kalasalingam Academy of Research and Education, Anand Nagar, Krishnankoil-626126, Tamilnadu, India

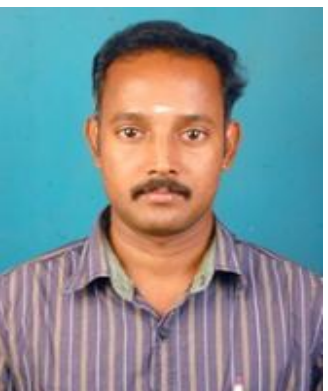

P. Manikandan received the B.E. degree in electronics and communication engineering from Krishnasamy college of Engineering, Cuddalore, India, in 2006.Also completed M.E. in Applied Electronics at Govt. College of technology, Coimbatore, India, in 2009. Currently working as Assistant Professor Department of electronics and communication engineering at Kalasalingam Academy of Research and Education, Srivilliputtur, India. 